\title{
O HERÓI EM CLARICE LISPECTOR: UMA LEITURA DE PERTO DO CORAÇÃO SELVAGEM
}

\author{
Angélica de Oliveira Castilho Pereira ${ }^{1}$
}

\begin{abstract}
Resumo
A ruptura com a estabilidade sugerida pelo cotidiano e o desmanchar de verdades construídas durante a trajetória das personagens são elementos comuns nas obras de Clarice Lispector e apontam a tragicidade como uma consequência da vida. O percurso de Joana, do livro Perto do coração selvagem, está vinculado a escolhas feitas por ela, anunciando a crise decorrente da liberdade parcial humana. Portanto, diferentemente do herói clássico, o herói moderno surge limitado, inquieto, contraditório, solitário.
\end{abstract}

\section{Palavras-chave}

Trágico. Herói. Modernidade. Clarice Lispector.

- Que é que eu faço para ser herói? Porque nos templos só entram heróis.

Clarice Lispector

(1994a, p. 59)

\section{1) Introdução}

Os objetivos deste artigo são apresentar a tragicidade na caminhada da personagem Joana advinda de seu projeto de vida - ser herói - e comentar o processo de escrita da autora Clarice Lispector como uma forma de ratificar tal projeto ao lançar mão de construção textual que opta por desvios, inovações, experimentos de linguagem.

Cabe salientar que não se pretende discutir se ocorre ou não o trágico nas obras modernas como um elemento caracterizador desse período estético. Se deseja apenas apontar a existência da tragicidade nos textos clariceanos, tendo em Perto do coração

\footnotetext{
${ }^{1}$ Doutora em Literatura Brasileira pela UFRJ. Atualmente, é professora adjunta do CAp-UERJ, atuando na Educação Básica e na Graduação, coordenando o estágio da instituição e participando como membro do projeto de extensão Jornal na Escola. É coautora dos livros Depois do fim: vida, amor e morte nas canções da Legião Urbana e autora do livro Literatura comparada: movimentos contemporâneos. Participa dos grupos de pesquisa LEDEN, do CAp-UERJ, sobre linguagens, transdisciplinaridade, tecnologia e ensino, e INTEGRA, da UFF, sobre produção oral e escrita, leitura, teoria e descrição gramatical da língua portuguesa. Contato: aocastilho@gmail.com
} 
selvagem (1943) o início de uma trajetória em busca de si mesmo que tornará não apenas Joana, mas todas as personagens clariceanas, seres errantes e em constante construção ${ }^{2}$.

Textos teóricos e textos clariceanos serão apresentados em diálogo, contribuindo para o encaminhamento da leitura do primeiro romance da autora. Cada citação propõe ressaltar o caráter trágico presente nas escolhas feitas por Joana e as relações existentes com a condição do ser humano no período moderno.

O ser humano moderno está inserido num contexto histórico em que parte das pessoas não acredita mais em progresso e em igualdade de chances para todos. Embora os conhecimentos tecnológicos e científicos tenham fascinado a humanidade nesse momento, esta não consegue conter o pessimismo que passa a dominar o meio urbano, afinal os sentimentos desamparo e incerteza evidenciados nas grandes guerras põem em xeque a posição de controle da própria vida e do mundo ao redor que a modernidade indicava. Acentua-se, portanto, a decepção e o descrédito das pessoas em relação a elas e ao mundo.

Inicia-se uma era trágica devido ao aspecto destrutivo de revoluções e guerras, ao egoísmo crescente que marca o capitalismo, ao desconhecimento de si mesmo representada por uma massa em busca de um destino único para todos. De um lado ou de outro, o homem perde a individualidade e encontra-se instável, vive cada minuto de forma incerta. O destino representado em escala social tem nos fatos históricos sua nova face. O final das fatalidades trágicas que o exercício da racionalidade e a ciência anunciavam na Modernidade não ocorre. (DOMENACH, 1968, p. 161)

O trágico torna-se presente no cotidiano e, na Literatura, não se limita a configurar apenas tragédias e passa a povoar outros gêneros textuais. Ele está presente na banalidade do dia a dia. Os seus mistérios visíveis manifestam-se nas ruas, entre as multidões, nos lares, e são considerados comuns.

\footnotetext{
2 O romance é a narrativa de uma busca por autoconhecimento e formação de personalidade, com um objetivo claro desde o início: tornar-se um herói. É uma existência de desencontros com o outro e perdas de pessoas, marcada por conflitos e questionamentos sobre a sua existência. Órfã de mãe e depois de pai, vai morar com a tia. Esta, não se sentindo à vontade com a menina, a manda para um internato. Adulta, casa com Otávio, mas a relação não é o que se entende por uma relação amorosa e se separam. Passa por outra experiência, tendo um caso com um estranho e acaba repentinamente. O romance termina com a personagem iniciando uma viagem.

Essa síntese não dá conta do que se conta de fato: os muitos pensamentos e sentimentos presentes nesses eventos da vida da personagem. São esses aspectos que pontuam os desencontros com o outro e com ela mesma que importam na narrativa sobre a vida de Joana. Clarice não narra fatos, narra a humanidade em descobrimento. Não existe resumo que dê conta desse aspecto.
} 
Na Antiguidade, havia um eixo, ou seja, um acontecimento muito significativo com a glorificação de um herói, após dores e batalhas, e revelava um arrebatamento patético que caracterizava o herói como um desmedido (BRANDÃO, 1990). Porém, na Modernidade, o glamour não encontra lugar, muito menos é possível executar feitos heroicos.

O ser moderno é excessivamente humano e é justamente a tomada de consciência da condição desamparada e solitária que possibilita a ele a vivência do sentimento trágico e, no caso da maioria das personagens clariceanas, em uma sociedade que tolhe, inibe e castra as mulheres, esse estado se torna mais patente ainda. Estar à margem e ser transgressor não são elementos que glorificam ou mesmo que facilitam a obtenção de algum prêmio, mas que conferem à personagem a dimensão de sua natureza.

A obra da escritora desenvolve um questionamento da existência presente na busca por reconstruir o indivíduo. A tragicidade dos caminhos das personagens inicia-se no momento da revelação do outro e delas mesmas, e prossegue com a liberdade sem perspectiva de futuro que as mesmas enfrentam.

Clarice Lispector traz figuras que se sensibilizam com o novo e o experimentam, mesmo que momentaneamente. Dentro desse cenário, o leitor depara-se com Joana, revoltada pelas limitações impostas pela condição de desamparo humana, pelo fato dela ser mulher, pelo sentimento de deslocamento no mundo.

A autora é dona de textos complexos, totalmente tocantes e próximos do cotidiano de qualquer leitor. Ela escreve sobre questões inquietantes e inerentes à natureza humana e sobre a dimensão que estas possuem na sociedade burguesa. No romance, temos a criança que não se encaixa em modelos apresentados e ao tentar entendê-los acaba por se considerar um pária. As realidades sufocadas, camufladas e mesmo proibidas das personagens demonstram com isto o grau de tragicidade oculto pela aparência da vida rotineira.

\section{Um ovinho vivo}

A autora Clarice Lispector (1920-1977) propõe olhares diversos e inquietos sobre o mundo, embora estes se direcionem para o rompimento de uma possível estabilidade que a rotina cotidiana desenha e, consequentemente, para se desfazer das verdades construídas ou mesmo adquiridas durante a trajetória das personagens. 
Tal quebra causa indagações que se tornam constantes e permanentes na obra da autora, como é evidenciado em O lustre (1946), claramente na expressão é “trágico viver" (LISPECTOR, 1995a, p. 153). A dimensão do trágico nas obras clariceanas é acompanhada pela paixão que arrebata o eu diante das decepções, buscando uma resposta lógica para dados subjetivos e singulares. Esse estado patético característico de Joana e de outras personagens clariceanas é oriundo do pathos, que etimologicamente significa "vivência", "desgraça”, "sofrimento", “paixão". A Modernidade possui um entendimento mais abrangente do que a Antiguidade, que chegava mesmo a atribuir ao arrebatamento patético uma anomalia - mesmo hoje há um sentido depreciativo em seu emprego -, por tirar o indivíduo do comedimento que a razão produz. Pathos vem a ser o sentimento que surge impetuoso de um choque, de uma forte decepção, como percebemos em momentos variados da narrativa de Perto do coração selvagem. Portanto, qualquer sentimento vivenciado por Joana pode conduzir a um arrebatamento patético, mostrando que o que faz surgir o pathos é a mudança da forma de ver um fato ou um ser. (STAIGER, 1975, p. 121-2)

Passar por tal experimentação patética faz parte da construção do herói e de suas situações de escolha e está presente desde a infância. A cena inicial é a primeira marca da personagem e possui na figura paterna a referência básica familiar de Joana. O capítulo "O Pai..." cria uma expectativa pelas reticências. Quais dados completariam o sentido dessa pontuação? Ainda se recuperando das reflexões do título, o leitor é lançado em um primeiro parágrafo com mais reticências, com onomatopeias, com personificações que criam um ambiente de sensações, um espaço fantástico construído pela visão de uma menina que percorrerá todo o capítulo. O leitor mais curioso pode indagar: de quem é a "orelha à escuta, grande, cor-de-rosa e morta" (LISPECTOR, 1995b, p. 19) que tudo ouve, mas que já não existe mais? Quem ainda está presente mesmo não estando? Pode ser a mãe ausente, pode ser o estado vigilante e sensível de Joana que tudo capta. As possibilidades de leituras caminham por múltiplas direções... Um fato é certo: tudo é percebido, tudo leva ao arrebatamento e à necessidade de compreensão.

Nesse lar, a criança está deslocada, entediada e não há comunicação entre o pai e a filha, as falas existem na conversa, mas não há entendimento:

- Papai, que é que eu faço?

- Vá estudar.

- Já estudei.

- Vá brincar. 
- Já brinquei.

- Então não amole. (LISPECTOR,1995b, p. 21-2)

Os olhares e os pensamentos não param, indagam e ficam sem respostas, a curiosidade não tem espaço. $O$ pai sente a situação e a fragilidade, mas não sabe como lidar com a menina, a qual enxerga como um ser estranho: "Um ovinho, é isso, um ovinho vivo. O que vai ser de Joana?”. (LISPECTOR, 1995b, p. 24)

Nota-se, no romance, uma abordagem da tragicidade compatível com a Modernidade, e capaz de reafirmar, por meio dessa multiplicidade de visão de mundo, a própria riqueza de concepções presentes nesse momento artístico.

O ser humano no século XX não espera soluções de ninguém, ao mesmo tempo em que está entregue aos papéis sociais pré-estabelecidos, também vive ao acaso, à classe social a que pertence, ou aos seus próprios atos e às consequências imprevisíveis destes. O pai de Joana aponta isso com clareza: "O pai medita um instante. Mas ninguém pode fazer alguma coisa pelos outros, ajuda-se. Anda tão solta a criança, tão magrinha e precoce..." (LISPECTOR,1995b, p. 24). As indagações, a solidão, a impotência e o espanto diante da falta de respostas atravessam a obra, são marcas que refletem revolta, contradições, pasmo do momento. Joana, assim como o ser humano moderno, sabe de seus limites e da ambiguidade que o caracteriza enquanto indivíduo e ser histórico. Eis a condição trágica permanecendo através do tempo e chegando à Modernidade.

Revelar, redescobrir, nomear, buscar a verdade última da vida são ideias que confirmam esse momento. Quando a ciência positivista apresentou o ser humano como resultado da evolução de uma espécie e não um ser feito à imagem e à semelhança de Deus, ele perdeu seu referencial e, consequentemente, a base da civilização cristã é questionada. A partir de então, busca-se, por vezes, preencher o vazio deixado. Joana possui a nostalgia de um tempo de certeza, bem marcado entre o bem e o mal, com parâmetros, nostalgia que a faz chegar a conclusões:

A certeza de que dou para o mal, pensava Joana.

O que seria então aquela sensação de força contida, pronta para rebentar em violência, aquela sede de empregá-la de olhos fechados, inteira, com a segurança irrefletida de uma fera? Não era no mal apenas que alguém podia respirar sem medo, aceitando o ar e os pulmões? Nem o prazer me daria tanto prazer quanto o mal, pensava ela surpreendida. Sentia dentro de si um animal perfeito, cheio de inconsequências, de egoísmo e vitalidade. (LISPECTOR,1995b, p. 25) 
Como descrito acima, a obra de Clarice Lispector questiona verdades tidas como absolutas, estando em sintonia com o século em que foi produzida. As personagens anseiam por respostas. Perguntas como "Quem sou eu?”, “O que sou eu?”, “Sou?” surgem como indagações angustiantes para "eus" que tiveram suas verdades abaladas ou mesmo destruídas.

De resposta, tal qual o mito da esfinge ${ }^{3}$, passa a pergunta e não se pode/sabe responder, como Joana não sabe e como depois é exposto diretamente em Um sopro de vida (1978): "Mas eu sou um enigma para a esfinge e no entanto não a devorei. Deciframe, disse eu à esfinge. E esta ficou muda." (LISPECTOR, 1994b, pp. 106-7) O desafio é encontrar o eu escondido dentro de si. A autora escreve sobre a relação conflituosa que a personagem estabelece primeiramente consigo mesma e depois com o outro.

Sendo a obra clariceana considerada por Alfredo Bosi uma escrita do interior e uma realização feliz do estilo que surge no panorama literário brasileiro nas décadas de 40 e 50 com o nome de "literatura intimista" (BOSI, 1993, p. 479), podemos ainda acrescentar que a subjetividade é o que interessa, pois nela é que está a grande ação da narrativa, é por meio do acesso aos pensamentos, sensações e sentimentos de Joana que o leitor consegue se deparar com a formação do herói e de sua tragicidade. Toda e qualquer ação de Joana só interessa porque é produto de uma intencionalidade.

Esse aspecto intimista traça o percurso da personagem, vinculando-a a escolhas próprias e aos acontecimentos externos, independentes de sua vontade. Esse último dado revela uma das crises da modernidade: o homem está "condenado" à liberdade, ainda que esta seja sempre parcial, não exista mais destino, a presença ou a ausência de Deus ainda seja significativa, sejam condições históricas e sociais os possíveis influenciadores externos, Joana, no lugar daquele que pode escolher, vacila entre duas situações: o conforto e o desamparo. Ao considerar essa experiência humana, a obra da autora revela a pluralidade dos momentos de arrebatamento trágico de um herói peculiar presente na Modernidade.

Esse livro de estreia de Clarice Lispector aborda uma temática permanente na obra da autora: a travessia do ser humano pela vida e sua relação com a morte. A autora, por sua vez, reconstrói a figura do herói trágico clássico que percorre obstáculos até uma morte inevitável. Nos textos clariceanos, o trágico não precisa ter na morte seu

\footnotetext{
3 “O homem” é a resposta de Édipo ao enigma da esfinge. O ser humano como resposta não se confirma como uma possibilidade na obra de clariceana.
} 
coroamento, o trágico é o que o Joana suscita em sua vida por meio de suas próprias escolhas. Ela não possui um destino pronto, é agente e não paciente, construtora e construção.

Por isso, ela caracteriza-se como transgressora e possuidora de um projeto de vida: “quando crescer vai ser herói...” (LISPECTOR, 1995b, p. 34). A revelação da intenção acrescida de reticências pelo pai indica a grandiosidade e ao mesmo tempo o desafio e desvio presentes na personalidade e nos caminhos escolhidos por Joana. O modelo não é de herói com as implicações que o termo ganha dentro da literatura que precede o modernismo. Joana quer protagonizar sem limitações para sua existência e ela também não quer ser heroína, isto poderia cair nos modelos que oprimem o feminino, a menina quer ser o que é reconhecido socialmente, quer ocupar um espaço igual e partilhar das mesmas condições (e tudo que estas trazem a um herói).

Tanto esta quanto as demais personagens são seres em construção, em busca de um destino de herói e que, por isso, se vasculham internamente: ideias, sentimentos, sensações. $\mathrm{O}$ ponto de partida para a indefinição do eu frente ao mundo, aos outros e a ele mesmo está nesse ar de rascunho de herói que as personagens clariceanas detêm. $\mathrm{O}$ incômodo de ser um eu para os outros sem saber-se ainda quem é para si marca o início das buscas e a necessidade de romper com a ordenação e a repetição apresentadas no cotidiano.

Considerando Joana uma personagem que sente revolta, que se vê deslocada, "um galho seco, espetado no ar" (LISPECTOR, 1995b, 41), mas que não se deixa levar por tais sentimentos e necessita seguir em frente, é possível afirmar que ela detém traços basilares para tornar-se um herói de acordo com a concepção clássica: ultrapassagem de limites, exercícios de habilidades, coragem para assumir seus desejos e exercê-los. Por outro lado, apresenta especificações próprias à condição da mulher e à do ser humano moderno. O que angustia a personagem clariceana é o ruir de concepções, é a paixão não só como sofrimento, mas como pasmo, despertar de emoções causados por um desmoronamento de mundo e, no caso de Joana, de um mundo que sempre lhe pareceu um não lugar para ela.

O conceito de herói trágico lhe cabe quando acredita ser senhora de sua vida, quando não entende qual o seu propósito de vida e quando indaga sobre tudo; afinal ela não ignora fatos, deseja saber o porquê do estranhamento causado por estar no mundo (DOMENACH, 1968, pp. 49-50). Porém, não é tratada pelo narrador como um ser especial, único. Joana não é diferente, apenas vê o mundo de maneira diversa. Nesse 
sentido, qualquer um pode ser herói desde que passe pelo mesmo processo e descobertas. A condição trágica da personagem surge, portanto, de uma fatalidade desconhecida e exterior à personagem, mas em conexão com sua ação no mundo.

O mundo da personagem é a organização das coisas feita por ela, é seu cosmos e, como este, relaciona-se com os elementos que o compõem. De acordo com esse princípio, é que se pensa em mundo moderno, ou seja, um espaço em que o ser humano é capaz de agrupar, selecionar e ordenar o mundo a partir e para suas necessidades e expectativas. $\mathrm{O}$ percurso de Joana é o caminho de quem coloca objetivos e verdades em xeque, e que, por isso, vivencia um desmoronamento da realidade e o sentimento trágico. É importante que o leitor perceba que a constituição do trágico baseia-se no aniquilamento da lógica de uma visão de mundo ou mesmo de um mundo enquanto espaço geográfico (STAIGER, 1975, pp. 140-1).

Por Joana perceber o mundo, o outro e a si mesma de forma singular, ela passa por situações de rompimento entre seus ideais e a realidade. Tais aspectos afastam-na das outras personagens e conferem tragicidade à sua vida. Trata-se de uma personagem inconformada com o espaço e a condição que ocupa, e ansiosa por mudanças. Ela anseia por ultrapassar o normal instituído socialmente, a fim de sentir, por um momento, a felicidade que intui, mas que não experimenta, criando um misto de desejo e insatisfação nesse processo de busca:

(...) Quem era ela? A víbora. Sim, sim, para onde fugir? Não se sentia fraca, mas pelo contrário possuída de um ardor pouco comum, misturado a certa alegria, sombria e violenta. Estou sofrendo, pensou de repente e surpreendeu-se. (...)? (LISPECTOR, 1995b, pp. 61-2)

Dentro dessa lógica, a maldade como uma forma de transgressão é necessária para libertar-se de seus invólucros sociais em busca de saber "quem é" e "por que é".

No íntimo da personagem, a fissura cresce a cada decisão, a cada reflexão, a cada sensação. Tal aspecto lança-a em um estado definitivo para a formação de caráter de herói, destacando-a como solitária e senhora de uma intuição lúcida. Tal exercício possibilita a certeza de que todo e qualquer momento de felicidade é furtivo e parte de ações e pensamentos transgressores, logo, ocupa o campo semântico da proibição. O conto "Felicidade Clandestina" pode ser trazido aqui para criar um diálogo entre esse projeto de herói que está presente na obra clariceana, revelando o caráter paradoxal e transgressor dos sentimentos no universo clariceano: “(...) A felicidade sempre iria ser clandestina para mim. Parece que eu já pressentia. (...)”. (LISPECTOR, 1998, p. 12) 
As personagens são representantes da condição necessária a cada herói moderno: fazer escolhas. Mas a escolha exclui e, como a felicidade advém de escolhas, nenhuma felicidade é insensata ou inocente, pois implica decisões e não atos involuntários. Nisto está uma das origens do trágico na Modernidade. Não é apenas uma visão sobre um acontecimento, é o estar no mundo como participante. (DOMENACH, 1968, p. 59)

A dimensão de superioridade encontrada nos modelos clássicos de herói não cabe nos textos de Clarice Lispector, pois são "eus" soltos no cotidiano sem elementos fantásticos, sem intervenções divinas. O que Joana apresenta de diferente é seu modo de ver. Ela não é uma semideusa nem possui superpoderes. A personagem cresce e continua deslocada, apenas se enxerga como o herói que planejou ser quando atinge a aceitação de quem é mergulha no mais básico, essencial, primeiro, não civilizado do ser vivo que é. Ao término da narrativa, Joana é lançada para um futuro além do texto, ao qual o leitor não tem acesso e só pode imaginar: tudo e nada podem acontecer e qualquer suposição não passa de vã especulação. O final em aberto está em conformidade com a falta de certezas presente na Modernidade, situando ainda mais a personagem nesse contexto, mas também dando ao leitor a visão panorâmica de um ser construído que passou de esboço para uma imagem na tela, porém ainda sujeita a mudanças.

Joana é um herói peculiar que para se estruturar fica à margem dos códigos de conduta, e percebe o cotidiano como elemento fundador de uma nova visão do mundo. Viver é que constitui o grande desafio. A visão crítica da personagem a expulsa da paz representada pelo falso conforto, falsa bondade:

\begin{abstract}
Sim, ela sentia dentro de si um animal perfeito. Repugnava-lhe deixar um dia esse animal solto. Por medo talvez da falta de estética. Ou receio de alguma revelação... Não, não, - repetia-se ela - é preciso não ter medo de criar. No fundo de tudo possivelmente o animal repugnava-lhe porque ainda havia nela o desejo de agradar e de ser amada por alguém poderoso como a tia morta. Para depois no entanto pisá-la, repudiá-la sem contemplações. Porque a melhor frase, sempre ainda mais jovem, era: a bondade me dá ânsias de vomitar. A bondade era morna e leve, cheirava a carne crua guardada há muito tempo. Refrescavam-na de quando em quando, botavam um pouco de tempero, o suficiente para conservá-la um pedação de carne morna e quieta. (LISPECTOR, 1995b, pp. 25-6)
\end{abstract}

Um aspecto relevante, nessa construção de um universo trágico, no qual as personagens estão inseridas, é a apropriação do grotesco como objeto literário, como no trecho anterior, contrariando, assim, o pressuposto aristotélico de que a imitação se 
pautaria na beleza contida em ações grandiosas e corajosas, enfim, a beleza interior dentro dos moldes gregos; o feio, ou seja, o que era moralmente disforme ficaria destinado à comédia e à provocação do riso (ARISTÓTELES, 1993, p. 263). Lispector utiliza as concepções de feio, mau e torna-as trágicos no romance em momentos de transgressão da ordem interior e exterior.

Aristóteles (384-322 a.C.) definiu a concepção de catarse como depuração, isto é, anulação das comoções e identificação com a ordem (1993, p. 260). Na obra clariceana, tal conceito é abolido, porque os textos chamam a atenção do leitor para angústias e inquietações do eu, universalizando e partilhando tais experiências e sensações, causando um reconhecimento de sentimentos, e não um afastamento provocado pela compaixão em relação às personagens, logo, ampliando as possibilidades de arrebatamento e de situações que proporcionam a vivência do trágico.

De acordo com Raymond Williams (1921-1988), na Modernidade:

(...) a definição de tragédia tornou-se uma definição centrada num tipo especial de ação espiritual, mais do que em acontecimentos específicos, e uma metafísica da tragédia substitui a ênfase moral, seja crítica, seja comum. Essa nova ênfase sobre a tragédia como um tipo específico, até mesmo raro, de ação e reação marca a principal emergência de ideias trágicas modernas. (WILLIAMS, 2002, p. 54)

Não é difícil reconhecer, nas palavras do escritor, a aproximação com o comportamento de Joana. Seu percurso é interior, e a narrativa, relato ora do momento de revelação por que passa a personagem, ora da vivência trágica. O pathos ultrapassa os fatos concretos e recai sobre as percepções de mundo do eu moderno. O ímpeto da personagem em busca de soluções resulta em transformação de suas visões de mundo.

Outras personagens apresentam-se igualmente desamparadas e abaladas, mas não se revoltam como Joana em grande parte de sua trajetória, pelo contrário, aceitam sua condição mais facilmente. Tal aspecto abre para posicionamentos variados, sem deixar de enfatizar que há aspectos constantes sobre o que é existir: a inquietude gerada pelas indagações sobre o que é ser uma pessoa, o que é viver; os desconfortos durante o percurso de busca por respostas; as sensações de angústia; a constatação do absurdo que, por vezes, é viver. Esses dilemas vividos por Joana e o fato de ser responsável pelas próprias escolhas surgem mesclados à felicidade de ser livre: 
(...) Ela notou que ainda não adormecera, pensou que ainda haveria de estalar em fogo aberto. Que terminaria uma vez a longa gestação da infância e de sua dolorosa imaturidade rebentaria seu próprio ser, enfim, enfim livre! (LISPECTOR,1995b, p. 223)

O peso de ser livre em um mundo onde não apenas a relação entre os homens e os conceitos morais estão sendo debatidos, mas também, cada conceito existente faz parte do estado trágico da personagem (WILLIAMS, 2002, p. 59), como incluir ou excluir a atuação de uma figura divina em sua vida: “(...) Não, não, nenhum Deus, quero estar só”. (LISPECTOR, 1995b, p. 223)

A obra clariceana atesta o dilema do homem moderno - e que já estava presente em períodos anteriores - entre acreditar em Deus ou não, expondo personagens que não creem e outras que acreditam em um Deus que esteja presente em todos os elementos que compõem o mundo. Tal versão justifica o surgimento da palavra "natureza" com letra maiúscula, ora sugerindo uma concepção de divindade, ora simbolizando a morte como integração da personagem ao cosmos.

A dualidade entre a presença e a ausência de Deus - este com todas as nuances e todos os aspectos salientados no decorrer das narrativas clariceanas - aponta questões permanentes na obra: Deus existe? O homem está só? As perguntas feitas sobre Deus, vida e morte são válidas? A obra clariceana não responde a tais perguntas. Contudo, a não resposta contribui para os sentimentos de solidão e de desamparo.

Esse percurso na contramão e no sentido correto é o paradoxo existencial de Joana a caminho da grande vivência dos sentidos:

(...) E um dia virá, sim, um dia virá em mim a capacidade tão vermelha e afirmativa quanto clara e suave, um dia o que eu fizer será cegamente seguramente inconscientemente, pisando em mim, na minha verdade, tão integralmente lançada no que fizer que serei incapaz de falar, sobretudo um dia virá em que todo meu movimento será criação, nascimento, eu romperei todos os nãos que existem dentro de mim, provocarei a mim mesma que nada há a temer, que tudo o que eu for será sempre onde haja uma mulher com meu princípio, erguerei dentro de mim o que sou um dia, (...) (LISPECTOR, 1995b, pp. 223-4)

A transgressão inserida no processo de transformação do próprio eu, na experiência interior feita de sensações, no abalo de um eu construído internamente é fundadora do momento trágico das personagens clariceanas. Elas são heróis por valorizarem cada aspecto de suas naturezas em meio às interferências externas e às barreiras construídas por elas mesmas. 
Seguindo o ímpeto por viver em plenitude, Joana herói passa por um processo de descoberta de vários "eus" e toma consciência de si e de suas contradições, o que esclarece o fato da personagem procurar escolher seus caminhos e ser responsável pelas opções feitas, apesar de todos os obstáculos e das condições sociais nas quais se encontra.

A consequência da liberdade é um dos elementos centrais para a construção do perfil de Joana e de outras personagens clariceanas. Elas libertam-se devido ao questionamento constante do mundo e à busca por identidade. A vontade é importante, porque possui força realizadora e transformadora. A ação - mesmo ocorrendo dentro da personagem - aponta para um problema a ser resolvido após a tomada de consciência. Em uma situação trágica, entende-se por problema a questão antecipada que terá que ser recuperada pelo eu. A pergunta “por que razão?” acompanha o homem até ele dar uma resposta ou mesmo não a encontrar, o que pode ser efetivamente uma resposta, como é o caso das personagens clariceanas. O problema e o pathos compõem o trágico. O pathos apresenta o querer, o abalo emocional; o problema indaga. (STAIGER, 1975, p. 139)

De um lado, a personagem questiona as verdades do mundo, do outro, a sociedade apresenta normas, surgindo o conflito. Sendo assim, a obra está em sintonia com o cenário da segunda metade do século XX que se desenhava em 1943: liberdade dependendo de condições sociais, religiosas, políticas. $O$ homem que ousa ser livre sofre as consequências de seus atos.

Joana não encara essa liberdade parcial como algo negativo, pelo contrário, é um prêmio: o autoconhecimento e o alcance do outro. Mas, antes disso, a personagem encontra-se em encruzilhadas, tem trajetórias com pontos altos e conflitantes, de ruptura com valores estabelecidos e surgimento de novas visões de mundo, e precisa fazer opções.

Mesmo com essa atitude positiva, Joana não neutraliza o fato de a liberdade ser limitada, de serem "joguetes do acaso" (HAUSER, 1995, p. 94), de acordo com uma concepção de acaso particular, pois não ocorre o controle absoluto nem por parte das personagens nem por parte de divindades. O que se apresenta ao leitor é um mundo sem destino. A Moira, divindade acima dos deuses, não atua na Modernidade. Sendo assim, o que influencia a vida das personagens não é unicamente a condição social em que vivem, mas também o outro. A fome, o desemprego, a desigualdade social, a miséria, a humilhação, a falta de respeito, o desamor são elementos que fazem parte do mundo em que elas estão. São situações quase coletivas. Mesmo quem está em uma posição social privilegiada não ignora a transitoriedade e a fragilidade do homem. 
Um aspecto heroico, entre outros, consiste na persistência em uma causa, mesmo que não se obtenha êxito ou premiação. No caso das personagens clariceanas, o desejo é rever verdades e, consequentemente, descobrir as verdades de suas naturezas.

Embora não existam eleitos nos textos de Clarice Lispector, apenas "eus" deslocados e com visões próprias de mundo, à medida que o termo "herói" é utilizado, traz concepções que contribuem para entender a inversão e a atualização de ideias culturalmente adquiridas através da história da humanidade sobre o que seja heroísmo. Por romper parâmetros e buscar a própria essência, quebrando barreiras pessoais e sociais, as personagens direcionam a coragem para a vontade de ir além, o que as leva à ação e à valorização do sentir em detrimento da racionalização do eu e do mundo. O grande desafio é ser um herói humano e não um semideus. Afinal, a personagem clariceana é também uma representante, que simboliza o desamparo, as indagações, os êxtases místicos ou não, as alegrias de uma época conflitante e paradoxal que é a Modernidade. $\mathrm{Na}$ obra da autora, a vida impõe que se viva, nem que seja por um breve momento.

Junito de Souza Brandão nos apresenta a natureza do herói como aquele que "seria o 'guardião, o defensor, o que nasceu para servir'” (1992, p. 15). Joana ressemantiza essa função ao trazer para a condição do ser humano moderno tais valores. Definitivamente, o herói clariceano é mais do que um guardião de sua pólis, ele é o defensor de si mesmo, é representante em sua maioria das muitas lutas da mulher no século XX e ainda hoje, é um lutador solitário que na exposição da individualidade aponta para muitos "eus" na mesma condição e fortalece o todo.

\section{3) Conclusão}

Clarice Lispector escreve sobre e a partir dos momentos em que a visão de personagens e narradores sobre o mundo é posta em dúvida. Por isso, entrelaça em seus textos experiências trágicas, atualizando, ao mesmo tempo, pensamentos e sentimentos de acordo com as novas concepções de tragicidade associadas à vida moderna. Esse olhar diferenciado é motivado por fatores de sua época: sentimento de solidão, fragilidade, desamparo e finitude. O ser humano na Modernidade e suas indagações são elementos centrais do romance apresentado, pois revela a procura do homem moderno por identidade e sentimento de pertencimento. O desenrolar dessa busca e os eventuais encontros causam rupturas e situações decisivas para Joana. 
O pensamento moderno tende a considerar a multiplicidade de tudo o que existe, e também a aceitar relações variadas entre o homem e o mundo. A cada mudança, um novo olhar surge. O descobrimento de faces ignoradas e, consequentemente, a mudança atravessam o romance, culminando com a certeza de que "qualquer luta ou descanso me levantarei forte e bela como um cavalo novo". (LISPECTOR, 1995b, p. 224)

Para tal revelação, as situações cotidianas, a batalha de existir a cada dia são o que interessa. A autora apresenta uma personagem em situações de profundo despertar. $\mathrm{O}$ rotineiro não exime o epifânico. Não existem ordens, hábitos, normas que impeçam a descoberta. Toda e qualquer banalidade cotidiana pode ser um elemento desencadeador de tragicidade.

\section{Referências}

ARISTÓTELES. Arte retórica e arte poética. Tradução de Antônio Pinto de Carvalho. Rio de Janeiro: Ediouro, 1993.

BOSI, Alfredo. História concisa da literatura brasileira. 3. ed. São Paulo: Cultrix, 1993.

BRANDÃO, Junito de Souza. Mitologia grega. 4. ed. Petrópolis: Vozes, 1992. v. 3 .

Teatro grego: tragédia e comédia. 5. ed. Petrópolis: Vozes, 1990.

DOMENACH, Jean-Marie. O retorno do trágico. Tradução de M. B. Costa. Lisboa: Moraes, 1968.

HAUSER, Arnold. História social da arte e da literatura. Tradução de Álvaro Cabral. São Paulo: Martins Fontes, 2003.

LISPECTOR, Clarice. Felicidade clandestina. Rio de Janeiro: Rocco, 1998. . O lustre. 9. ed. Rio de Janeiro: Francisco Alves, 1995a.

. Onde estivestes de noite. 7. ed. Rio de Janeiro: Francisco Alves, 1994a. . Perto do coração selvagem. 16. ed. Rio de Janeiro: Francisco Alves, 1995 b. . Um sopro de vida. 10. ed. Rio de Janeiro: Francisco Alves, 1994 b.

STAIGER, Emil. Conceitos fundamentais da poética. Tradução de Celeste Aída Galeão. Rio de Janeiro: Tempo Brasileiro, 1975.

WILlIAMS, Raymond. Tragédia moderna. Tradução de Betina Bischof. São Paulo: Cosac \& Naif, 2002. 


\title{
THE HERO IN CLARICE LISPECTOR: A READING OF PERTO DO CORAÇÃO SELVAGEM
}

\begin{abstract}
The rupture with stability suggested by daily life and the dismantling of truths built during the characters' trajectory are common elements in the works of Clarice Lispector and point out the tragedy as a consequence of life. Joana's path, from the book Near to the Wild Heart, is linked to choices made by her, announcing the crisis resulting from human partial freedom. Therefore, unlike the classic hero, the modern hero appears limited, restless, contradictory, solitary.
\end{abstract}

\section{Keywords}

Tragic. Hero. Modernity. Clarice Lispector. 